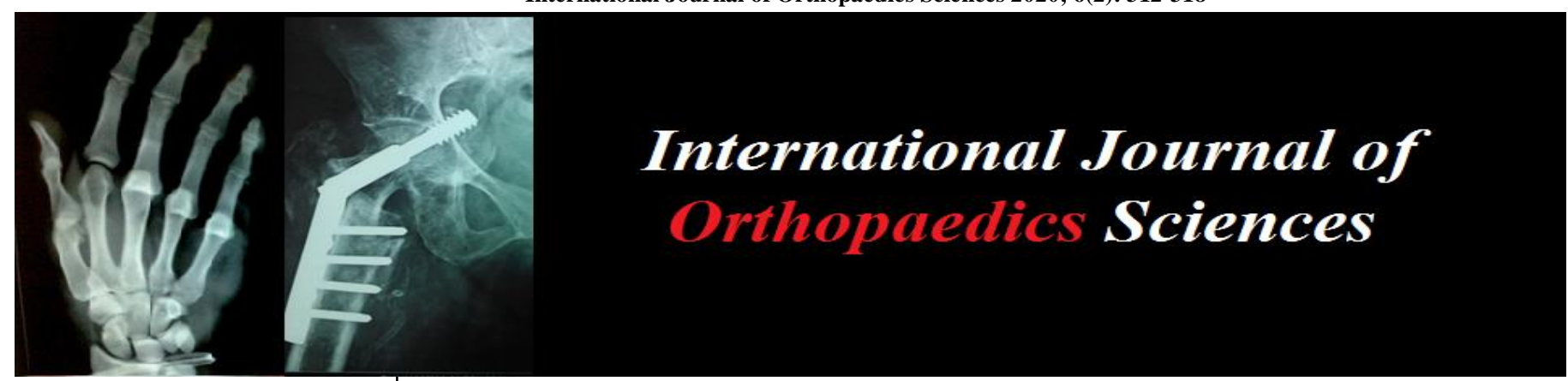

E-ISSN: 2395-1958

P-ISSN: 2706-6630

IJOS 2020; 6(2): 312-318

(C) 2020 IJOS

www.orthopaper.com

Received: 26-02-2020

Accepted: 28-03-2020

\section{Mohan NS}

Department of Orthopedics

Sanjay Gandhi Institute of

Trauma and Orthopedics,

Jayanagar East, Bangalore,

Karnataka, India

\section{Sindhu B}

Department of Orthopedics Sanjay Gandhi Institute of Trauma and Orthopedics, Jayanagar East, Bangalore, Karnataka, India

Shankar Gouda Patil Department of Orthopedics Sanjay Gandhi Institute of Trauma and Orthopedics, Jayanagar East, Bangalore, Karnataka, India
Corresponding Author: Mohan NS

Department of Orthopedics Sanjay Gandhi Institute of Trauma and Orthopedics, Jayanagar East, Bangalore, Karnataka, India

\section{Functional outcome of short vs long segment transpedicular fixation in thoracolumbar junction burst fractures-A comparative study}

\author{
Mohan NS, Sindhu B and Shankar Gouda Patil
}

DOI: https://doi.org/10.22271/ortho.2020.v6.i2e.2059

\section{Abstract}

Objective: To assess the functional and radiological outcome of thoracolumbar junction burst fractures treated by long and short segment fixation.

Methods: A prospective study included 40 patients with thoracolumbar junction burst fractures, 20 patients treated with long and 20 patients treated with short segment posterior transpedicular screw fixation at spine injury center, Sanjay Gandhi Institute of trauma and orthopedics, Bangalore from January 2017 to February 2019. Clinical outcome was assessed using Modified Macnab criteria, ODI scoring system and VAS score and radiological assessment was done using Cobb angle, Becks index and segmental kyphotic deformity.

Results: Our study showed predominant male population (80\%) with working age group (31-40yrs) who had unstable thoracolumbar junctional burst fractures. Most common mode of injury was fall from height (60\%). Patients were divided randomly into 2 groups and group 1 (20 patients) had undergone short segment transpedicular screw fixation, while group 2 (20 patients) had undergone long segment fixation. Regular follow up was done at 3, 6,9 months and 1 year and all patients were evaluated thoroughly for radiological and functional outcomes. At the end of 12 months of follow up, according to modified Macnab criteria, $28.6 \%$ had excellent, $70 \%$ had good and 5\% had fair outcomes in short segment fixation while $45 \%$ had excellent and 55\% had good outcomes in long segment fixation. Mean VAS scores in short segment fixation was 1.33 and long segment 1.10, mean ODI score in short segment was 6.30 and long segment was 6.80. Mean kyphotic deformation before surgery was 14.05 degrees and after correction was 9.2 degrees in short segment and before surgery was 15.45 degrees and after correction was 5.6 degrees in long segment fixation. Our study showed long segment fixation have better results in terms of correction of deformity. Mean Cobb's angle in short segment fixation was 15.8 degrees before surgery and 12.5 degrees after fixation, in long segment fixation before surgery was 18.6 degrees and after surgery was 7.15 degrees. Becks index in short segment fixation before surgery was 0.68 and 0.80 after surgery, and in long segment fixation was 0.59 before surgery and 0.82 after surgery.

Conclusion: Our data identified a trend towards better clinical and radiological outcomes in the long segment transpedicular fixation, compared to the short segment transpedicular group.

Keywords: Thoracolumbar junction burst fractures, short segment, long segment, cobb angle, transpedicular fixation, kyphotic deformation

\section{Introduction}

The most common area of injury to the axial skeleton is the thoracolumbar junction. Forces acting along the long stiff kyphotic thoracic spine switches abruptly into the mobile lordotic lumbar spine at the thoracolumbar junction. Biomechanically, this transition zone is susceptible to injury and is the most commonly injured portion of the spine, motor vehicle accidents are the leading cause of injury followed by falls and sports related injuries ${ }^{[1]}$.

The thoracolumbar region is one of the most common regions for spine injures (about90\%), and burst fractures comprise about 10-20\% of such injuries [2,3]. Burst fractures are characterized by failure of the middle and anterior spinal columns secondary to axial compression ${ }^{[2]}$. Neurological injury complicates $19 \%$ to $50 \%$ fractures of thoracolumbar region ${ }^{[4]}$.

Burst fractures are radiographically characterized by posterior vertebral body angle exceeding 
$100^{\circ}$, reduction in posterior vertebral height, widened inter pedicle distance, posterior cortical line disruption, and posterior vertebral body break, which may be associated with varying degrees of canal stenosis ${ }^{[5]}$. Indications for operative treatment may include neurologic deficit, unstable fracture, severe kyphosis greater than $25^{\circ}$, canal compromise greater than $50 \%$, or posterior ligamentous complex injury, $>50 \%$ loss of vertebral body height ${ }^{[6,7]}$. Other arguments for surgery include decreased rates of neurologic deterioration, improved kyphosis correction, and facilitation of early mobilization that may decrease complications from prolonged bed rest ${ }^{[8,9]}$.

Various surgical techniques, including posterior Short segment or long segment pedicle screw fixation, direct anterior decompression through corpectomy, and combined methods through anterior and posterior spinal approaches, have since arisen for treatment of thoracolumbar burst fractures ${ }^{[10-12]}$. However, the decision of surgical methods still remains controversial ${ }^{[13,14]}$.

The introduction of transpedicular instrumentation systems were considered highly beneficial because of its distinct advantages such as rigid segment fixation, stabilization of 3 columns, least failure at bone metal interface, early postoperative mobilization with least complications ${ }^{[15]}$. SSPF (short segment pedicle screw fixation) is the use of pedicle screw instrumentation one level cephalad to and one level caudad to the fractured vertebra was introduced with an aim to preserve the motion segments along with an attempt to improve fusion rates, ability to obtain reduction and maintain sagittal contour which would eventually lead to lower incidence of residual pain ${ }^{[16]}$.

Long segment pedicle screw fixation LSPF (two level above and two level below the fractured vertebral body) has been thought to have better mechanical stability compared to SSPF and lesser screw back out rates. But it has more loss of motion segments, longer operative time, and more amount of bleeding and muscle damage ${ }^{[17]}$.

However the decision about the appropriate level of segmental fixation remains controversial. Hence this study was held to compare the functional as well as radiological outcome of long versus short segment fixation.

\section{AIMS}

To assess the functional and radiological outcome of thoracolumbar junction burst fractures treated by long and short segment fixation

\section{Methodology \\ Objective}

- To analyze and compare the results of functional and radiological outcome in thoracolumbar junction burst fractures and dislocations fixed with long segment transpedicular fixation and short segment transpedicular fixation.

- To facilitate early mobilization of patients and thus helping easy nursing care of patients in order to provide a stable and pain free spinal column.

\section{Study Design: Prospective comparative study}

\section{Inclusion criteria}

- Patients with age 20-60 yrs

- Patients with TLICS (thoracolumbar injury classification and severity score)

- $\quad$ score $>4$

- Patients with AO classification type A3and A4
- Unstable thoracolumbar junctional burst fractures involving T12 and L1 vertebra

\section{Exclusion criteria}

- Patients with age $<20$ and $>60$ yrs.

- Patients with co-morbid conditions not permitting for surgery.

- Patients with associated injuries like pelvic injury, head injury.

- Patients having complete paraplegia with bowel and bladder involvement.

- Pathological fracture.

- Multiple fracture $>3$ vertebrae.

\section{Materials \& methods}

A prospective study of 40 patients of age 20-60 years with Post Traumatic thoracolumbar burst fractures in the Department of Orthopedics, Sanjay Gandhi Institute of Trauma and Orthopedics, Bangalore between January 2018 to February 2019.

The skeletal system was examined to rule out associated injuries. The patient's spine was examined for any swelling, contusion, tenderness, hematoma, gibbus or step off. Antero posterior and lateral plain X rays, CT scans, and MRI were taken to identify all injuries and to assess the severity and nature of the injury. AO classification was used for categorization and TLICS scoring for management purpose. Thoracolumbar junction was considered as T12 and L1 vertebral fractures.

\section{Unstable burst fractures were defined by following criteria}

1. Injury with 2-3 spinal column involvement.

2. Loss pf vertebral body height by $>40 \%$.

3. Kyphotic angle $>25 \%$.

4. Spinal canal narrowing $>40 \%$.

5. Incomplete neurological deficit.

40 patients were randomly divided into 2 groups of 20 patients each. Group $1(n=20)$ were treated with SSPF (short segment transpedicular instrumentation spanning 2 vertebra, one cephalad and one caudal to the fractured vertebra) and group $2(n=20)$ with LSPF (instrumentation spanning 2 vertebra cephalad and 2 vertebra caudal to the fractured vertebra). Procedure was carried out in prone position with posterior midline approach. Pedicle screws used were 40-50 $\mathrm{mm}$ long and $6.5 \mathrm{~mm}$ size depending upon the vertebra. Bilateral instrumentation was applied and stabilized with cross links cephalad and caudal to the fracture in order to augment the torsional rigidity. Decompression was performed in cases with severe neurological deficit, in order to remove the retro pulsed bone fragments or disc remnants from spinal canal.

\section{Post-operative protocol}

- On the second postoperative day, patients were encouraged to sit upright with brace support.

- $\quad 2^{\text {nd }}$ POD dressing was done and drain was removed.

- Patients were encouraged full weight bearing mobilization with brace.

- $14^{\text {th }}$ POD suture removal was done.

- Initial 3months-Mobilization with brace, increasing the activities gradually.

- After 3 months-patient can resume his routine activities. 
For functional assessment, Modified Macnab's criteria and Oswestry disability index and VAS score used, and for radiological assessment Cobb's angle, segmental kyphotic deformation and Beck's index was used. Follow up was done at 3,6 and 12 months post operatively.

Cobb's angle: Is defined as the angle formed between a line drawn parallel to superior end plate of one vertebra above the fracture and a line drawn parallel to the inferior end plate of the vertebra one level below the fracture.

Beck index: Is a measurement of kyphotic segmental deformity and is the ratio of anterior vertebral height to posterior vertebral height at the level of deformed segment.

\section{Modified Macnab’s Criteria}

Table 1: Table showing modified MCNAB'S criteria

\begin{tabular}{|c|l|}
\hline Excellent & No pain, no restriction of mobility, return to normal work and level of activity \\
\hline Good & Occasional non-radicular pain, relief of presenting symptoms, able to return to modified work \\
\hline Fair & Some improved functional capacity, still handicapped and/or unemployed \\
\hline Poor & $\begin{array}{l}\text { Continued objective symptoms of root involvement, additional operative intervention needed at index level irrespective of } \\
\text { length of postoperative follow up }\end{array}$ \\
\hline
\end{tabular}

\section{Oswestry Disability Index}

Table 2: Table showing oswestry disability index

\begin{tabular}{|c|c|}
\hline $20 \%-$ & $\begin{array}{l}\text { The patient can cope with most living activities. Usually no treatment is indicated apart from advice on lifting sitting } \\
\text { and exercise. }\end{array}$ \\
\hline $\begin{array}{l}21-40 \% \text { - moderate } \\
\text { disability }\end{array}$ & $\begin{array}{l}\text { The patient experiences more pain and difficulty with sitting, lifting and standing. Travel and social life are more } \\
\text { difficult and they may be disabled from work. Personal care, sexual activity and sleeping are not grossly affected and } \\
\text { the patient can usually be managed by conservative means. }\end{array}$ \\
\hline $\begin{array}{l}41 \%-60 \% \text { - severe } \\
\text { disability }\end{array}$ & $\begin{array}{l}\text { Pain remains the main problem in this group but activities of daily living are affected. These patients require a detailed } \\
\text { investigation. }\end{array}$ \\
\hline $61 \%-80 \%$ - crippled & Back pain impinges on all aspects of the patient's life. Positive intervention is required. \\
\hline $81 \%-100 \%$ & These patients are either bed-bound or exaggerating their symptoms \\
\hline
\end{tabular}

\section{Results}

In our study most patients were male of working age group $31-40$ years. $85 \%$ were males and $15 \%$ females

Table 3: table showing distribution of age group in SSPF and LSPF groups

\begin{tabular}{|c|c|c|c|c|}
\hline Age group & Long segment & percentage & Short segment & percentage \\
\hline $20-30$ yrs & 3 & $15 \%$ & 4 & $20 \%$ \\
\hline $31-40$ yrs & 10 & $50 \%$ & 9 & $45 \%$ \\
\hline $41-50$ yrs & 5 & $25 \%$ & 4 & $20 \%$ \\
\hline$>50 y r s$ & 2 & $10 \%$ & 3 & $15 \%$ \\
\hline
\end{tabular}

Majority of mode of injuries were fall from height. $52 \%$ were AO type 4 injuries and $48 \%$ were AO type 3 injuries. Majority of the patients had L1 vertebral fractures. The clinical outcomes studies were as follows

\section{Modified Macnab's Criteria}

At the end of 12 months group 1 (SSPF) had 28.6\% excellent, $70 \%$ good and $1 \%$ fair outcome and group 2(LSPF) had $45 \%$ excellent, 55\% good outcomes. Both groups had statistically insignificant $\mathrm{P}$ value though long segment fixation had more number of excellent and good results.

Table 4: Comparison of modified McNab criteria between 2 groups

\begin{tabular}{|c|c|c|c|c|c|c|c|c|}
\hline & & \multirow{2}{*}{ Group } & \multirow{2}{*}{$\mathbf{N}$} & \multirow{2}{*}{ Mean (SD) } & \multirow{2}{*}{ Range } & \multirow{2}{*}{ Median (Q1-Q3) } & \multicolumn{2}{|c|}{ Mann Whitney U Test } \\
\hline & & & & & & & U Statistic & p-value \\
\hline \multirow{6}{*}{ ODI score } & \multirow{2}{*}{3 Mon } & Group 1 & 21 & $7.20(2.17)$ & $4-10$ & $8(5.25-9)$ & \multirow{2}{*}{155.5} & \multirow{2}{*}{$0.23(\mathrm{NS})$} \\
\hline & & Group 2 & 20 & $8.70(3.69)$ & $3-16$ & $8.5(6-11.75)$ & & \\
\hline & \multirow{2}{*}{6 Mon } & Group 1 & 21 & $6.40(1.90)$ & $3-12$ & $6(5.25-7)$ & \multirow{2}{*}{142.5} & \multirow{2}{*}{$0.11(\mathrm{NS})$} \\
\hline & & Group 2 & 20 & $7.70(2.83)$ & $4-15$ & $7(6-8.75)$ & & \\
\hline & \multirow{2}{*}{12 Mon } & Group 1 & 21 & $6.30(2.58)$ & $3-13$ & $5.5(4.25-8)$ & \multirow{2}{*}{168.5} & \multirow{2}{*}{$0.39(\mathrm{NS})$} \\
\hline & & Group 2 & 20 & $6.80(2.38)$ & $3-12$ & $6.5(5-8.75)$ & & \\
\hline
\end{tabular}

\section{ODI Score}

Majority of post-operative patients have minimal ODI with mean of 6.30 in SSPF and 6.80 in LSPF. Both groups did not have much of difference.

Table 5: Comparison of ODI score between study groups.

\begin{tabular}{|c|c|c|c|c|c|c|}
\hline & \multirow{2}{*}{ MCNAB criteria } & \multicolumn{2}{|c|}{ Group } & & \multicolumn{2}{|c|}{ Chi Square Test } \\
\hline & & Group 1 & Group 2 & & Chi square value & P-value \\
\hline \multirow{6}{*}{3 Mon } & \multirow{2}{*}{ Excellent } & 7 & 7 & 14 & \multirow{6}{*}{-} & \multirow{6}{*}{$1.00(\mathrm{NS})^{\#}$} \\
\hline & & $33.3 \%$ & $35.0 \%$ & $34.1 \%$ & & \\
\hline & \multirow{2}{*}{ Fair } & 1 & 1 & 2 & & \\
\hline & & $4.8 \%$ & $5.0 \%$ & $4.9 \%$ & & \\
\hline & \multirow{2}{*}{ Good } & 13 & 12 & 25 & & \\
\hline & & $61.9 \%$ & $60.0 \%$ & $61.0 \%$ & & \\
\hline & & & & & & \\
\hline 6 Mon & Excellent & 7 & 12 & 19 & 2.93 & $0.09(\mathrm{NS})$ \\
\hline
\end{tabular}




\begin{tabular}{|c|c|c|c|c|c|c|}
\hline & & $33.3 \%$ & $60.0 \%$ & $46.3 \%$ & & \\
\hline & \multirow{2}{*}{ Good } & 14 & 8 & 22 & & \\
\hline & & $66.7 \%$ & $40.0 \%$ & $53.7 \%$ & & \\
\hline \multirow{6}{*}{12 Mon } & \multirow{2}{*}{ Excellent } & 6 & 9 & 15 & \multirow{4}{*}{1.19} & \multirow{4}{*}{$0.28(\mathrm{NS})$} \\
\hline & & $28.6 \%$ & $45.0 \%$ & $36.6 \%$ & & \\
\hline & \multirow{2}{*}{ Good } & 14 & 11 & 25 & & \\
\hline & & $70 \%$ & $55.0 \%$ & $62.5 \%$ & & \\
\hline & \multirow{2}{*}{ FAIR } & 1 & 0 & 1 & & \\
\hline & & $5 \%$ & $0 \%$ & $5 \%$ & & \\
\hline
\end{tabular}

\section{VAS Score}

Table 6: Table showing comparision VAS score between 2 groups

\begin{tabular}{|c|c|c|c|c|c|c|c|c|}
\hline & & \multirow[b]{2}{*}{ Group } & \multirow{2}{*}{$\mathbf{N}$} & \multirow[b]{2}{*}{ Mean (SD) } & \multirow{2}{*}{ Range } & \multirow{2}{*}{ Median (Q1-Q3) } & \multicolumn{2}{|c|}{ Mann Whitney U Test } \\
\hline & & & & & & & U Statistic & p-value \\
\hline \multirow{6}{*}{ VAS score } & \multirow{2}{*}{3 Mon } & Group 1 & 21 & $1.81(0.68)$ & $1-3$ & $2(1-2)$ & \multirow{2}{*}{192} & \multirow{2}{*}{$0.60(\mathrm{NS})$} \\
\hline & & Group 2 & 20 & $1.70(0.66)$ & $1-3$ & $2(1-2)$ & & \\
\hline & \multirow{2}{*}{6 Mon } & Group 1 & 21 & $1.48(0.60)$ & $1-3$ & $1(1-2)$ & \multirow{2}{*}{200} & \multirow{2}{*}{$0.76(\mathrm{NS})$} \\
\hline & & Group 2 & 20 & $1.40(0.50)$ & $1-2$ & $1(1-2)$ & & \\
\hline & 12 Mon & Group 1 & 21 & $1.33(0.66)$ & $1-3$ & $1(1-1.5)$ & 179 & $0.22(\mathrm{NS})$ \\
\hline & & Group 2 & 20 & $1.10(0.31)$ & $1-2$ & $1(1-1)$ & & \\
\hline
\end{tabular}

Group 1 (SSPF) had VAS score of 1.33 and group 2 (LSPF) had vas score 1.10 at 12 months of follow up. Both groups had similar mean VAS score at the end of 12 months of follow up.

\section{Radiological outcome \\ Cobbs angle}

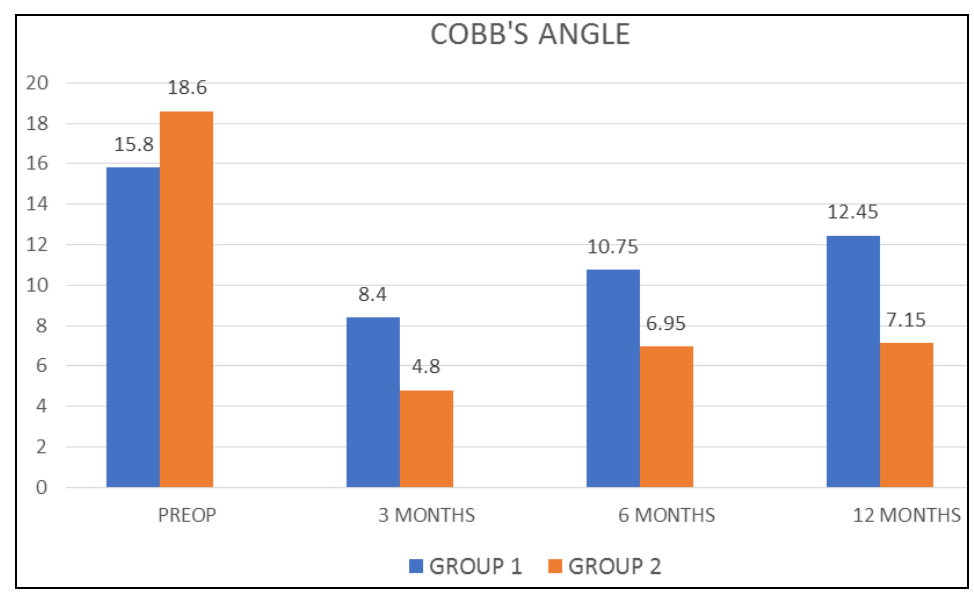

Chart 1: chart comparing COBB'S angle between 2 groups

GROUP 2 (LSPF) have better Cobb's angle correction from 18.6 to 7.15 and both groups have statistically significant $p$ value.

\section{Segmental kyphotic deformity}

At the end of 12 months both groups have statistically significant kyphotic deformation. Long segment group have a better correction from 15.45 degrees preop to 5.6degree post op.

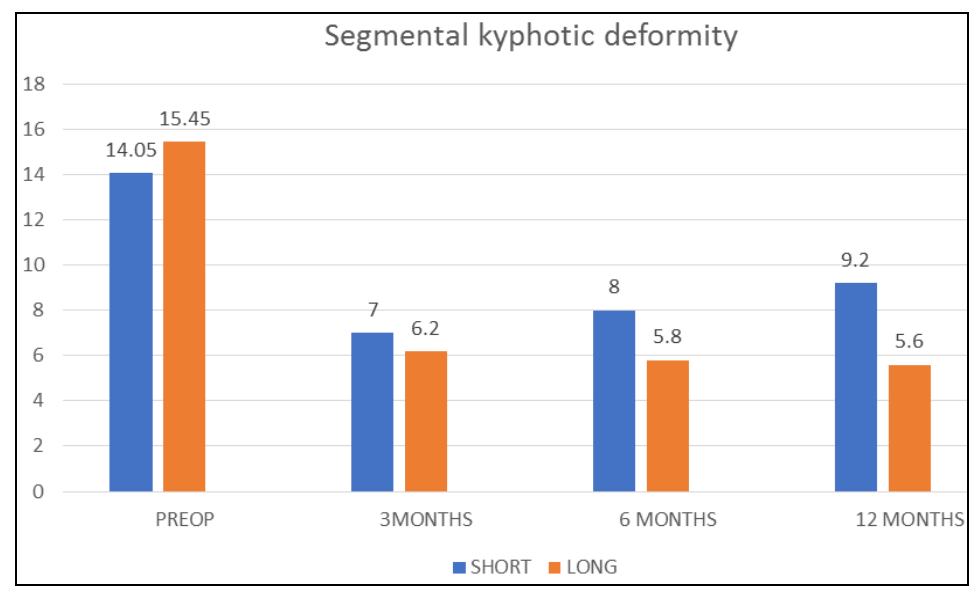

Chart 2: chart showing comparison of segmental kyphotic deformity between 2 groups. 


\section{Becks Index}

This study shows there is statistically significant difference in Beck's index in both groups from 0.68 to 0.85 in SSPF and from 0.59 to $0.82 \mathrm{LSPF}$. Long segment fixation have better Beck's index at the end of 12 months.

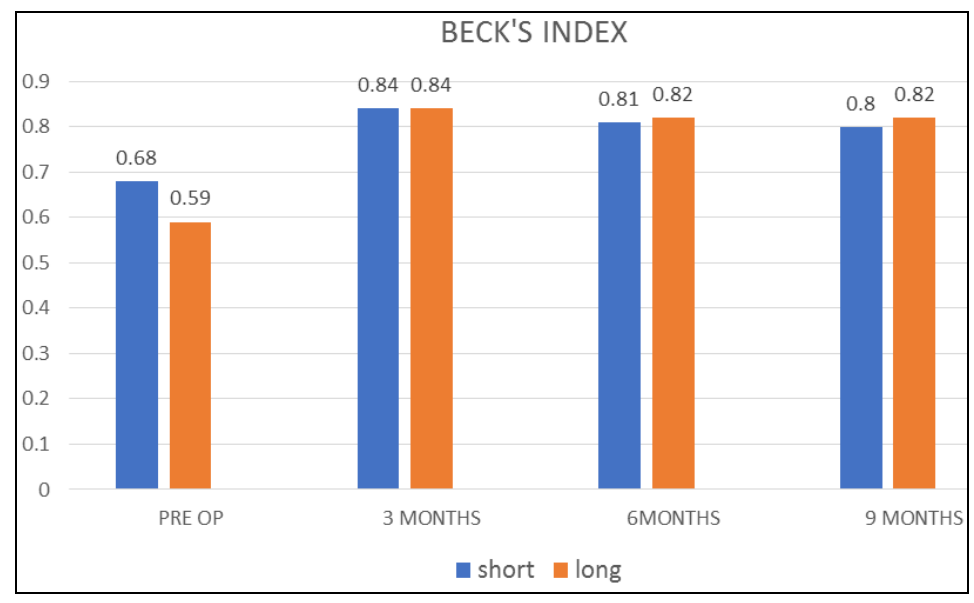

Chart 3: chat showing comparison of BECK'S index between 2 groups.

\section{Complications}

3 case of implant failure was seen in short segment fixation, 2 in the form of screw back out and one in the form of pedicle screw breakage. No implant failure in long segment cases. 2 cases of superficial wound infection was seen in long segment fixation which subsided with regular dressing and antibiotics. 1 case of grade 2 bed sore in short segment and 2 cases of grade 1 and 2 bed sores each in long segment fixation. One case of progressive neurological deficit in short segment group was seen.

\section{Discussion}

Thoracolumbar injuries of the spine are most common in whole of spinal trauma. These thoracolumbar spinal injuries are most commonly caused by fall from height. In our study we found that fall from height constitutes about $60 \%$ of spinal injuries and RTA causes $40 \%$ of spinal injuries. The thoracolumbar junction is the most common area of injury to the axial skeleton as it is the transition between normal thoracic kyphosis to flexible lumbar lordosis. Vertebral fractures in this area are usually extremely unstable and kyphotic deformity is often of significant degree. $(18,19)$ Therefore, inserting the screws only one level above and below the fractured segment might not have provided adequate stability. In our study $55 \%$ of fractures were of L1 vertebra and $45 \%$ were of T12 vertebra.

Depending on the type of spinal injury, associated spinal and non-spinal injuries occur in upto $50 \%$ of patients (Cotler et al 1986, Court-Brown 1988). Intra thoracic injuries in $20 \%$ of patients while intra-abdominal injuries in $10 \%$ patients and associated skeletal injuries in up to $20 \%$ of the patients. In our study calcaneum fractures were most commonly seen. 1 patient has associated neck of femur fracture and 2 patients had bilateral calcaneum fracture and one patient with unilateral calcaneum fracture.

A burst fracture is caused by axial compression and accompanied with retro pulsed bone fragments into spinal canal. Not only fracture of posterior cortex of vertebral body but also retropulsion of the fractured fragments into the spinal canal and an increase of inter-pedicular distance are presented on radiologic examinations. The operative treatment for burst fractures is generally performed when there is neurological or mechanical instability and its goal is decompression of spinal canal and nerve root for neurological recovery, restoration and maintenance of vertebral height and spinal alignment, rigid fixation for early ambulation and rehabilitation, and prevention of progressive neurological injury and kyphotic deformity. McAfee et al. ${ }^{[20]}$. Emphasized that PLC is an important structure for fracture stability and classified burst fractures into stable and unstable injuries based on disruption of posterior elements. In our study AO classification was used to classify and TLICS scoring was used to assess the severity of injury. 52\% were AO type 3 injuries and $48 \%$ were AO type 4 injuries.

Transpedicular screws and rod system is currently the standard in fixation of thoracolumbar spine. Posterior transpedicular screw fixation initially was reported by Boucher ${ }^{[21]}$ in 1959. Transpedicular screw instrumentation maintains reduction until bony union is achieved.

Regular follow up was done and clinical outcomes were assessed using modified Mcnab criteria according to which at the end of 12 months $28.6 \%$ had excellent, $70 \%$ had good and $5 \%$ had fair outcomes in short segment fixation while $45 \%$ had excellent and 55\% had good outcomes in long segment fixation. Mean VAS scores in short segment fixation was 1.33 and long segment 1.10 , mean ODI score in short segment was 6.30 and long segment was 6.80 .

In thoracolumbar burst fractures, introduction of transpedicular screw insertion by Roy-Camille made possible the frequently used posterior approach ${ }^{[15]}$. Gurr and McAfee [20] demonstrated that long segment pedicle screw instrumentation, which included two levels above and below the fractured vertebra, offered adequate stiffness to stabilize an unstable thoracic or lumbar burst fractures. SSPF is frequently regarded as the procedure of choice because it offers advantages such as incorporating fewer motion segments in the fusion, shorter operative time and fewer blood transfusions. Katonis et al. found ${ }^{[22]}$ that one-level above and one-level below the fracture in the lumbar area formed a rigid construct with no correction loss. Butt et al. [23], reported success of short segment pedicle screw fixation in thoracolumbar burst fractures; however, the $40 \%$ (20 out of 50 patients) hardware failure rate that they reported is worrisome.

Radiological assessment was done using Cobb's angle, Beck's index and segmental kyphotic deformation. Mean kyphotic deformation before surgery was 14.05 degrees and after correction was 9.2 degrees in short segment and before surgery was 15.45 degrees and after correction was 5.6 degrees in long segment fixation. Our study showed long 
segment fixation have better results in terms of correction of deformity. Mean cobb angle in short segment fixation was 15.8 degrees before surgery and 12.5 degrees after fixation, in long segment fixation before surgery was 18.6 degrees and after surgery was 7.15 degrees. Becks index in short segment fixation before surgery was 0.68 and 0.80 after surgery, and in long segment fixation was 0.59 before surgery and 0.82 after surgery.

Peters et al. ${ }^{[24]}$, in their biomechanical study comparing short segment versus long segment fixation, found that long posterior fixation was the stiffest with and without anterior column augmentation in all loading conditions. The use of screws two above and two below has shown to not only enhance the stability but also allow effective reduction of kyphotic deformity ${ }^{[25]}$.

McLain ${ }^{[18]}$ studied patients with severe spinal fractures treated with segmental fixation and found that those who had treated with long surgical reconstructions had not more impairment than those who had treated with shorter constructs and less dissection. Serin et al. ${ }^{[26]}$, reported that four levels posterior fixation is superior to two levels posterior fixation and that this fixation is more stable when using an accessory offset hook. Tezeren et al. ${ }^{[12]}$ demonstrated that final outcome regarding sagittal index and anterior body compression is better in the LS instrumentation group than in the SS instrumentation group.

The aim of the current study is to compare the SS fixation to LS fixation as far as the surgical correction is concerned. These surgical methods were compared using the statistical analysis of specific indexes (Cobb angle, kyphotic deformation and Beck Index) in order to investigate which technique gives better results according to these indexes. According to the statistical analysis using the Mann-Whitney test there is a significant difference for both the Cobb angle and the kyphotic deformation, between the two different study groups.

Kim et al. reported that short segment fixation with screw placement in fractures vertebra provided additional stability, maintaining local kyphosis and better kyphotic deformity correction and reported the correction loss of 3.70 of Cobb's angle at the last follow up ${ }^{[27]}$. In our study correction loss of Cobb's angle was 4.05 degrees in SSPF and 2.35 degrees in LSPF.

In our study we had 3 cases of implant failure $(15 \%)$ in short segment fixation in the form of screw backout and screw breakage and no cases of implant failure in long segment fixation. 2 cases of superficial wound infection was seen in long segment fixation which subsided with regular dressing and antibiotics.

\section{Limitations}

- Follow up evaluation was limited to 1 year which is considered to be a short term

- We did only decompression and posterior stabilization with transpedicular screws without fusion with cage or bone graft.

\section{Conclusion}

There was no significant difference between long and short segment fixation in terms of clinical outcome even though long segment group had more number of excellent and good results. Long segment transpedicular fixation even though had a prolonged operative time and blood loss, gives a better radiological result in the form of kyphotic deformity correction.

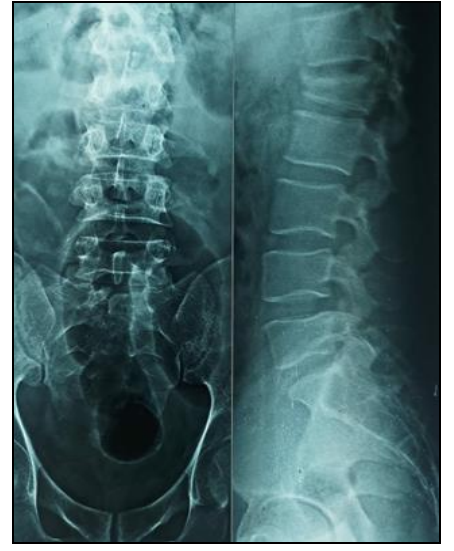

Fig 1: Preop AP and lateral view radiograph showing L1 burst fracture

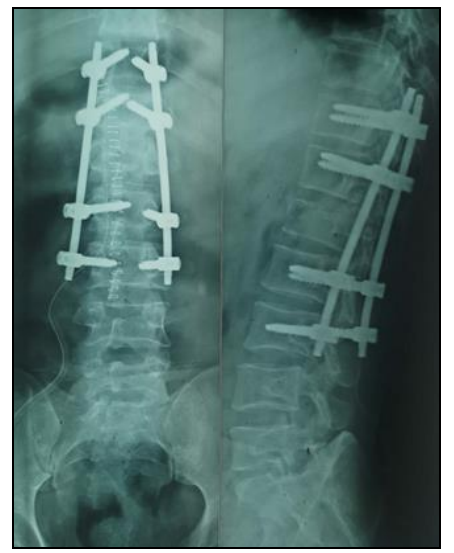

Fig 2: Post-operative AP and lateral view radiograph showing long segment fixation

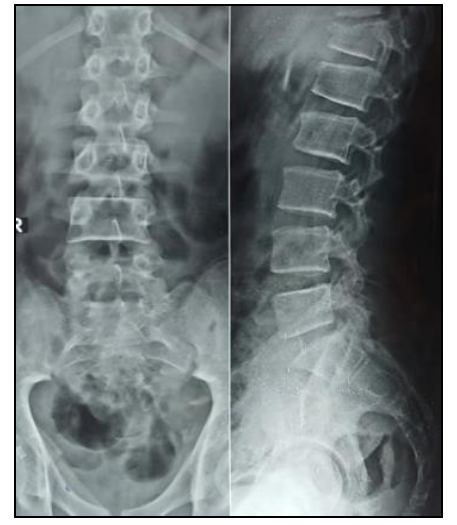

Fig 3: Preop AP and lateral view radiograph showing T12 fracture

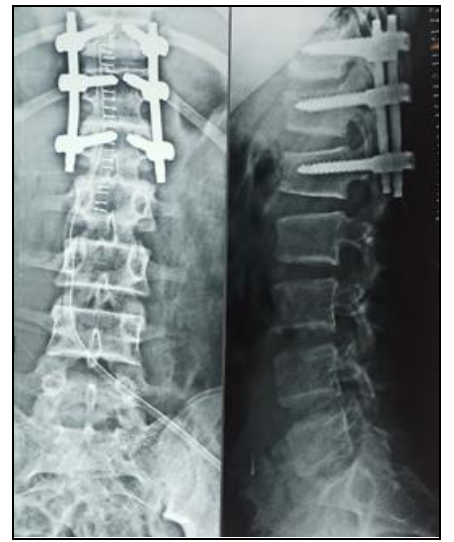

Fig 4: Post-operative AP and lateral view radiograph showing short segment fixation 


\section{References}

1. Makintubee S, Herdon W, Istre GR. PC. Epidemiology of traumatic spinal cord injury and acute hospitalization and rehabilitation changes for spinal cord injuries in Oklahoma. AMJ Epidemiol. 1994; 139:37-47.

2. Denis F. The Three Column Spine and Its Significance in the Classification of Acute Thoracolumbar Spinal Injuries: Spine. 1983; 8(8):817-31.

3. Evaluation of surgical treatment for burst fractures. PubMed-NCBI [Internet]. [cited 2020 Jan 26]. Available from: https://www.ncbi.nlm.nih.gov/pubmed/2218713

4. Yu SW1, Fang KF, Tseng IC, Chiu YL, Chen YJ, CW. Surgical outcomes of short-segment fixation for thoracolumbar fracture dislocation. Chang Gung Med J 2002 Apr254253-9.

5. Atlas SW, Regenbogen V, Rogers LF KK. The radiographic characterization of burst fractures of the spine. AJR Am J Roentgenol 1986; 735:75-82.

6. Dai LY, Jiang SD, Wang XY, Jiang LS. A review of the management of thoracolumbar burst fractures. Surg Neurol. 2007; 67(3):221-31.

7. Reid DC, Hu R, Davis LA, Saboe LA. The Nonoperative Treatment of Burst Fractures of the Thoracolumbar Junction: J Trauma Inj Infect Crit Care. 1988; 28(8):1188-94.

8. Andress HJ, Braun H, Helmberger T, Schürmann M, Hertlein H, Hartl WH. Long-term results after posterior fixation of thoraco-lumbar burst fractures. Injury. 2002; 33(4):357-65.

9. Akbarnia BA1, Crandall DG, Burkus K, MT. Use of long rods and a short arthrodesis for burst fractures of the thoracolumbar spine. A long-term follow-up study. J Bone Jt Surg Am 1994; 76(11):629-35.

10. Parker JW, Lane JR, Karaikovic EE, Gaines RW. Successful short-segment instrumentation and fusion for thoracolumbar spine fractures: a consecutive $4 \$ 1 / 2 \$$-year series. Spine. 2000; 25(9):1157-1170.

11. Sasso RC, Best NM, Reilly TM, McGuire RA. Anterioronly stabilization of three-column thoracolumbar injuries. J Spinal Disord Tech. 2005; 18:S7-14.

12. Tezeren G, Kuru I. Posterior fixation of thoracolumbar burst fracture: short-segment pedicle fixation versus long-segment instrumentation. J Spinal Disord Tech. 2005; 18(6):485-8.

13. Chen HH, Wang WK, Li KC, Chen TH. Biomechanical effects of the body augmenter for reconstruction of the vertebral body. Spine. 200415; 29(18):E382-387.

14. Dai LY, Jiang LS, Jiang SD. Anterior-only stabilization using plating with bone structural autograft versus titanium mesh cages for two- or three-column thoracolumbar burst fractures: a prospective randomized study. Spine. 2009; 34(14):1429-35.

15. Roy-Camille R, Saillant G, Mazel C. Internal fixation of the lumbar spine with pedicle screw plating. Clin Orthop. 1986; (203):7-17.

16. Panjabi MM, Oxland TR, Lin RM, McGowen TW. Thoracolumbar burst fracture. A biomechanical investigation of its multidirectional flexibility. Spine. 1994; 19(5):578-85.

17. Saboe LA, Reid DC, Davis LA, Warren SA, Grace MG. Spine trauma and associated injuries. J Trauma. 1991; 31(1):43-8.

18. McLain RF. Functional outcomes after surgery for spinal fractures: return to work and activity. Spine. Discussion Z6. 2004; 29(4):470-7.
19. McLain RF. The biomechanics of long versus short fixation for thoracolumbar spine fractures. Spine. 2006; 31(11S):S70-S79.

20. McAfee PC, Yuan HA, Fredrickson BE, Lubicky JP. The value of computed tomography in thoracolumbar fractures. An analysis of one hundred consecutive cases and a new classification. J Bone Joint Surg Am. 1983; 65(4):461-73.

21. Boucher HH. A method of spinal fusion. J Bone Joint Surg Br. 1959; 41-B(2):248-59.

22. Katonis PG, Kontakis GM, Loupasis GA, Aligizakis AC, Christoforakis JI, Velivassakis EG. Treatment of unstable thoracolumbar and lumbar spine injuries using CotrelDubousset instrumentation. Spine. 1999; 15(24-22):23527.

23. Butt MF, Farooq M, Mir B, Dhar AS, Hussain A, Mumtaz M. Management of unstable thoracolumbar spinal injuries by posterior short segment spinal fixation. Int Orthop. 2007; 31(2):259-64.

24. Bolesta MJ, Caron T, Chinthakunta SR, Vazifeh PN, Khalil S. Pedicle screw instrumentation of thoracolumbar burst fractures: Biomechanical evaluation of screw configuration with pedicle screws at the level of the fracture. Int J Spine Surg. 2012; 6:200-5.

25. Lazaro BCR, Deniz FE, Brasiliense LBC, Reyes PM, Sawa AGU, Theodore N, et al. Biomechanics of thoracic short versus long fixation after 3-column injury. J Neurosurg Spine. 2011; 14(2):226-34.

26. Serin E, Karakurt L, Yilmaz E, Belhan O, Varol T. Effects of two-levels, four-levels, and four-levels plus offset-hook posterior fixation techniques on protecting the surgical correction of unstable thoracolumbar vertebral fractures: a clinical study. Eur J Orthop Surg Traumatol. 2004; 14(1):1-6.

27. Kim HY, Kim HS, Kim SW, Ju CI, Lee SM, Park HJ. Short Segment Screw Fixation without Fusion for Unstable Thoracolumbar and Lumbar Burst Fracture : A Prospective Study on Selective Consecutive Patients. J Korean Neurosurg Soc. 2012; 51(4):203-7. 